Jurnal Semarak,Vol. 3,No.1, Februari 2020, Hal (52- 59)

@Prodi Manajemen Fakultas Ekonomi Universitas Pamulang

\title{
ANALISIS POTENSI LITERASI INFORMASI MAHASISWA PRODI MANAJEMEN UNIVERSITAS PAMULANG
}

\author{
Krida Puji Rahayu, S.Pd., M.Pd. \\ Asisten Ahli Fakultas Ekonomi Universitas Pamulang \\ Email : dosen01666@unpam.ac.id mailto:dosen02277@unpam.ac.id
}

\begin{abstract}
ABSTRAK
Karya ilmiah ini bertujuan untuk mengetahui sejauhmana korelasi potensi literasi informasi mahasiswa khususnya prodi manajemen Universitas Pamulang dengan menggunakan ACRL (Assosiation Colllege Of Research Library). Mahasiswa tingkat akhir program studi S1 Manajemen yang sedang menyusun skripsi menjadi populasi dalam penelitian dengan teknik purposive sampling non probablilty yang berjumlah 100 responden. Metode penelitian deskriptif kuantitatif digunakan dengan teknik analisis regresi sederhana pada program IBM SPSS 24. Analisis statistik terdiri dari uji prasyarat analisis data dan uji hipotesis. Berdasarkan hasil pengolahan data menunjukan bahwa potensi literasi informasi mahasiswa prodi Manajemen sebesar 78,4\% sedangkan 21,6\% dijelaskan oleh variabel lain yang tidak diteliti dalam penelitian ini. Dengan demikian, koleksi perpustakaan dan layanan perpustakaan secara bersama-sama dapat mempengaruhi dan memiliki korelasi positif terhadap potensi literasi informasi mahasiswa. Adanya peningkatan pada kualitas koleksi dan layanan perpustakaan akan mempengaruhi dan meningkatkan potensi literasi informasi mahasiswa Universitas Pamulang.
\end{abstract}

Kata kunci : Literasi informasi, perpustakaan perguruan tinggi Universitas Pamulang.

\begin{abstract}
This scientific work aims to know a correlation of the potential literacy of student information especially in the management of Pamulang University by using ACRL. The population in the study is the final level student S1 Management course which is composing a thesis with a non probablilty purposive sampling technique amounting to 100 respondents. Quantitative descriptive research methods are used with simple regression analysis techniques on IBM SPSS 24 programs. Statistical analysis consists of the prerequisite test of data analysis and hypothesis tests among them; (1) Validity test, (2) realistic test, (3) test normality, (4) test multicolinearity, (5) test F and (6) test T. Based on the results of data processing shows that the potential information literacy of students Management is $78.4 \%$ while the $21.6 \%$ is described by other variables not examined in this study. Thus, the collection of libraries and library services library can jointly influence and have a positive correlation to the potential literacy of student information. The increase in the quality of collection, service library will influence and increase the potential information literation of the students of Pamulang University.
\end{abstract}

Keywords: Information literacy, University Library of Pamulang College. 


\section{PENDAHULUAN}

\section{A. Latar Belakang}

Hartaji (2012: 5) menyatakan, "Mahasiswa adalah seseorang yang sedang dalam proses menimba ilmu ataupun belajar dan terdaftar sedang menjalani pendidikan pada salah satu bentuk perguruan tinggi yang terdiri dari akademik, politeknik, sekolah tinggi, institut dan universitas". Menurut peraturan Kepala Perpustakaan Nasional RI No 13 Tahun 2017 Tentang Standar Nasional Perpustakaan Perguruan Tinggi "perpustakaan perguruan tinggi merupakan bagian integral dari kegiatan pendidikan, penelitian, dan pengabdian kepada masyarakat dan berfungsi sebagai pusat sumber belajar untuk mendukung tercapainya tujuan pendidikan yang berkedudukan di perguruan tinggi". Potensi literasi informasi pemustaka (pengguna perpustakaan) menjadi salah satu umpan balik positif dari kualitas performa perpustakaan.

Association of college and Research (ACRL) memiliki standar kompetensi literasi informasi yang telah dikaji oleh Dewan Direksi ACRL pada 18 Januari 2000, atau dikenal dengan istilah ACRL 2000. Koleksi, layanan dan tenaga perpustakaan merupakan elemen yang saling berkaitan dalam menunjang potensi literasui informasi pemustaka.

Literasi informasi pada perguruan tinggi bermanfaat dalam pembelajaran sepanjang hayat yang akan menjadi dasar dalam pekerjaan dan karier di masa depan (ACRL, 2000:4). Di samping itu, literasi informasi merupakan potensi dasar bagi seorang sarjana yang berkualitas, yang perlu didukung oleh berbagai element pendidikan didalamnya. Salah satu potensi dasar dari literasi informasi adalah minat baca. Indonsia belum mendapatkan peringkat dari lembaga survey nasional maupun internasional dalam hal minat baca baik dari tahun ke tahun. Berikut hasil survey yang telah dilakukan oleh lembaga survey terkait literasi informasi dalam enam tahun terakhir:

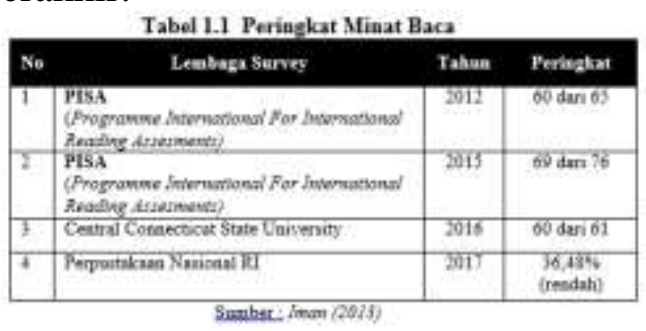

Beberapa survei internasional mengenai literasi bekerjasama dengan Kemendikbud yang diikuti oleh Indonesia, diantaranya PISA (Programme for International Reading Assesments) yang diinisasi oleh OECD (Organization for Economic Coorporation and Development) yang diselenggarakan setiap tiga tahun sekali sejak tahun 2000 dan diikuti oleh 72 negara di seluruh dunia dan PIRLS (Progress in International Reading Literacy Study) yang diselenggarakan setiap lima tahun sekali, sejak tahun 2001 yang diikuti oleh 45 negara partisipan.

Hal ini tentu menjadi tanggung jawab berbagai pihak, khususnya bidang pendidikan untuk meningkatkan potensi literasi informasi sebuah bangsa. Pendidikan menjadi sebuah rumah filter yang seyogyanya mampu menjadikan para penghuninya 
kompeten dalam mengidentifikasi informasi, mengolah, mengevaluasi dan menggunakan sebuah informasi.

Oleh karena itu, universitas sebagai pendidikan tinggi memiliki kontribusi yang cukup besar dalam membentuk generasi information society yang berkualitas.

Peran dan tanggung jawab pendidikan tinggi untuk menjadikan mahasiswa sebagai peserta didik secara aktif agar mampu mengembangkan potensi dirinya dan menggali pengetahuan secara mendalam, menjadi salah satu tanggung jawab moral sebuah perpustakaan perguruan tinggi. Tidak hanya sebagai center of knowledge pada perguruan tinggi, perpustakaan memliki ruang tersendiri dalam meningkatkan potensi literasi informasi pemustaka potensialnya, sehingga akan berdampak signifikan dalam proses belajar mengajar bagi mahasiswa.

Dari UU no 43 Tahun 2007 butir (c) bahwa, "Dalam rangka meningkatkan kecerdasan kehidupan bangsa, perlu ditumbuhkan budaya gemar membaca melalui pengembangan dan pendayagunaan perpustakaan sebagai sumber informasi yang berupa karya tulis, karya cetak, dan/atau karya rekam". Hal ini menandakan bahwa koleksi perpustakaan merupakan sebuah kebutuhan primer dalam rangka ikhtiar meningkatan minat baca pemustaka. Koleksi perpustakaan tidak bisa dijadikan satu indikator utama dalam langkah meningkatkan potensi literasi informasi mahasiwa. Layanan perpustakaan menjadi sebuah integrasi perpustakaan kepada pemustaka dalam pemenuhan kebutuhan informasi.

Layanan dalam perpustakaan terbagi menjadi dua, yakni layanan sirkulasi dan layanan referensi. "Setiap perpustakaan mengembangkan layanan perpustakaan sesuai dengan kemajuan teknologi informasi dan komunikasi" (UU No 43 Tahun 2007 Bab V pasal 14 alinea 3). Perkembangan IT saat ini berkembang pesat, yang berdampak pada deras nya informasi.

Oleh karena itu, dibutuhkan seorang pustakawan yang bisa menjadi mediator, fasilitator dan edukator literasi informasi untuk membantu pemustaka untuk memenuhi kebutuhan informasi. Literasi informasi merupakan sebuah kompetensi mendasar yang akan berdampak besar bagi setiap ilmu yang dipelajari oleh mahasiwa terlebih pada mahasiswa tingkat akhir yang sedang mengerjakan skripsi. Kebutuhan akan informasi ilmiah terbaru menjadikan mahasiswa dipaksa untuk berfikir kritis menanggapi derasnya informasi.

\section{B. Rumusan Masalah}

Rumusan masalah dalam penelitian ini antara lain sebagai berikut :

1. Sejauh mana korelasi koleksi perpustakaan terhadap potensi literasi informasi mahasiswa Program studi S1 Manajemen Universitas Pamulang?

2. Sejauh mana korelasi layanan perpustakaan terhadap potensi literasi informasi mahasiswa Program studi S1 Manajemen 
Universitas Pamulang?

\section{Tujuan Dari Penelitian}

Adapun tujuan penelitian yang ingin dicapai dalam penelitian ini adalah:

1. Untuk mengetahui sejauhmana korelasi koleksi perpustakaan terhadap potensi literasi informasi mahasiswa Program studi S1 Manajemen Universitas Pamulang.

2. Untuk mengetahui sejauhmana korelasi layanan perpustakaan terhadap potensi literasi informasi mahasiswa Program studi S1 Manajemen Universitas Pamulang.

\section{TINJAUAN PUSTAKA}

\section{A. Literasi Informasi}

Di negara maju, seperti Amerika, beberapa disiplin ilmu mempertimbangkan literasi informasi sebagai hasil utama siswa di perguruan tinggi (American Library Association, 2000: 4). Oleh karena membangun pemelajar seumur hidup merupakan salah satu misi pendidikan tinggi.

Hal ini sangat sejalan dengan apa yang dinyatakan Candy, Crebert, dan O'Leary yang dikutip oleh Iman (2013: 82) mengatakan "Access to, and critical use of information and of information technology is absolutely vital to lifelong learning, and accordingly no graduate - can be judged educated unless he or she is information literate".

(Hasugian, 2009: 204)

\section{B. Koleksi Perpustakaan}

Menurut buku Pedoman

Pembinaan Koleksi dan

Pengetahuan Literature (1998:2),

"Koleksi perpustakaan adalah semua bahan pustaka yang dikumpulkan, diolah, dan disimpan untuk disajikan kepada masyarakat guna memenuhi kebutuhan pengguna akan informasi". Hal senada juga disampaikan Ade Kohar (2003:6), "Koleksi perpustakaan adalah yang mencakup berbagai format bahan sesuai dengan perkembangan dan kebutuhan alternatif para pemakai perpustakaan terhadap media rekam informasi".

Dengan kata lain koleksi perpustakaan baiknya disesuaikan dengan kebutuhan para civitas akademik setempat, agar bisa mendukung proses kegiatan belajar mengajar secara optimal. Koleksi perpustakaan menjadi materi dalam peningkatan kemampuan literasi informasi pemustaka.

\section{c. Layanan Perpustakaan}

Pengertian sirkulasi ini mencakup pengertian yang lebih luas, yakni semua bentuk kegiatan pencatatan yang berkaitan dengan pemanfaatan, dan penggunaan koleksi dengan tepat guna dan tepat waktu untuk kepentingan pengguna jasa perpustakaan (Lasa Hs, 2008: 213).

\section{METODE PENELITIAN}

Jenis penelitian deskriptif kualitatif digunakan untuk menjawab hipotesis penulis. Mahasiswa tingkat akhir yang sedang melaksanakan skripsi program S1 Manajemen 2019 Universitas Pamulang berjumlah 1800 mahasiswa/i merupakan populasi penelitian. "Objek atau nilai yang diteliti dalam populasi disebut unit analisis atau elemen populasi" (Hasan, 2002: 58). 
Teknik pengambilan sampel menggunakan purposive sampling non probability yang berjumlah 100 responden.

Metode pengumpulan data-data yang digunakan diantaranya:

1. Data utama atau Primer

Dilakukan dengan cara melakukan pengamatan langsung dan penyebaran kuesioner yang dibagikan kepada responden penelitian, yakni mahasiswa program studi S1 Manajemen dan S1 Akutansi Universitas Pamulang.

2. Data Sekunder

Adalah data penelitian yang bersumber dari beberapa buku, literatur, jurnal online, tulisan/artikel yang diperoleh melalui internet, serta data juga diperkuat dengan gambaran umum, struktur organisasi dan wawancara dengan beberapa narasumber di lingkungan kampus Universitas Pamulang.

\section{HASIL PENELITIAN}

\section{A. Uji Validitas dan Reliabilitas}

1. Uji validitas Berdasarkan Variabel Komunikasi $\left(\mathrm{X}_{1}\right)$

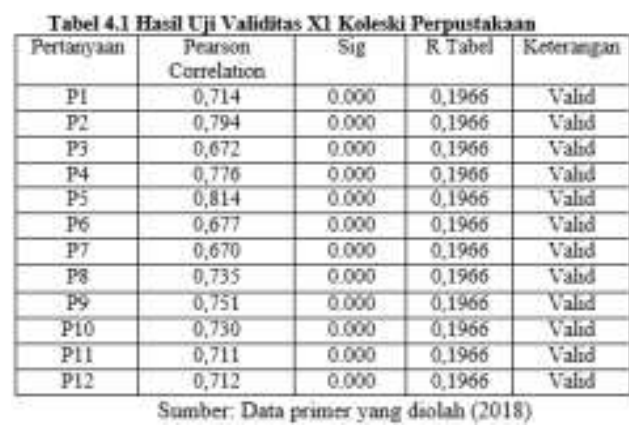

Tabel 4.1 menunjukkan bahwa 12 item pertanyaan dari variabel X1 (Koleksi Perpustakaan) adalah valid. Hal ini berarti bahwa pernyataanpernyataan pada variabel $\mathrm{X} 1$ telah sesuai dengan penelitian ini.
2. Uji Validitas Berdasarkan Variabel Layanan Perpustakaan (X2)

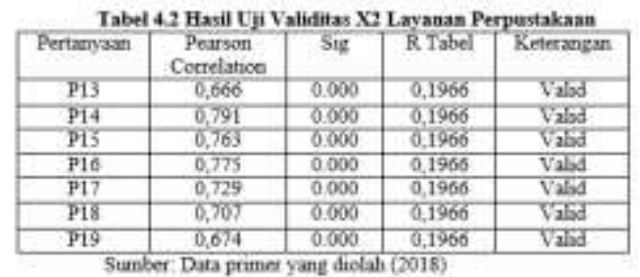

Tabel 4.2 menunjukkan bahwa 7 item pertanyaan adalah valid yang mana 7 butir pertanyaan tersebut memiliki tingkat signifikan dibawah 0,05 atau nilai dari Pearson Correlation memiliki nilai lebih besar dari $r$ tabel. Hal ini berarti bahwa pernyataan-pernyataan pada variabel X2 telah sesuai dengan penelitian ini.

3. Uji Reliabilitas Instrumen

Tabel 4.3

Hasil Uji Reliabilitas Koleksi Perpustakaan Reliability Statistics

\begin{tabular}{|r|r|}
\hline $\begin{array}{c}\text { Cronbach's } \\
\text { Alpha }\end{array}$ & N of Items \\
\hline .920 & 12 \\
\hline
\end{tabular}

Sumber: Data Primer yang diolah (2018)

Tabel 4.3 menunjukkan hasil uji reliabilitas Koleksi Perpustakaan adalah nilai yang menunjukkan nilai Cronbach alpha secara gabungan, yang mana hal ini menunjukkan tentang apakah keselurahan pertanyaan sudah reliabel. Dapat dilihat bahwa nilai Cronbach alpha menunjukkan hasil yang reliabel. Dengan demikian, instrumen layak digunakan dalam penelitian.

\section{Tabel 4.4}

Hasil Uji Reliabilitas Layanan Perpustakaan Reliability Statistics

\begin{tabular}{|r|r|}
\hline $\begin{array}{c}\text { Cronbach's } \\
\text { Alpha }\end{array}$ & N of Items \\
\hline .849 & 7 \\
\hline
\end{tabular}

Sumber: Data Primer yang diolah (2018)

Tabel 4.4 adalah nilai yang menunjukkan nilai Cronbach alpha 
secara gabungan, yang mana hal ini menunjukkan tentang apakah keselurahan pertanyaan sudah reliabel. Dapat dilihat bahwa nilai Cronbach alpha menunjukkan hasil yang reliabel sehingga dapat digunakan sebagai alat penelitian.

\section{B. Uji Prasyarat Data}

1. Uji Normalitas

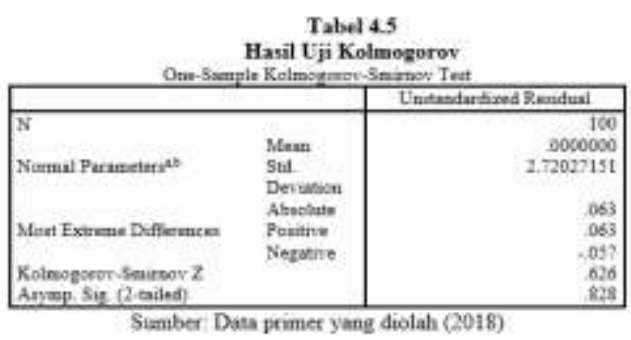

Uji Kolmogorov Smirnov dari hasil penelitian ini memiliki nilai signifikasni sebaesar 0,828 yang menandakan bahwa data tersebut memenuhi asumsi normalitas yaitu nilai tersebutdiatas 0,05 . Berdasarkan hal tersebut, data awal terdistribusi normal.

\section{Uji Multikolinearitas}

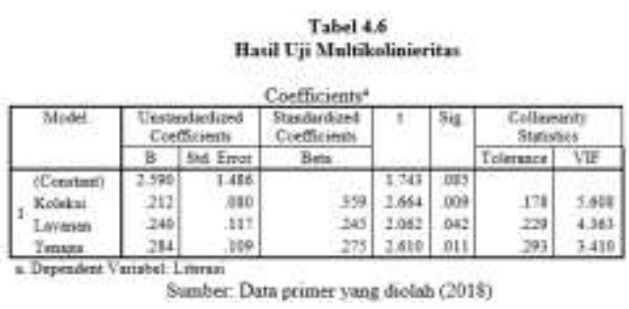

Tabel 4.6, menunjukkan bahwa tidak ada variabel yang memiliki nilai tolerance kurang dari 0,01 yang berarti tidak ada korelasi antar variabel independen yang nilainya lebih dari 95\%. Hasil perhitungan nilai Variance Inflation Factor (VIF) juga menunjukkan hal yang sama yakni tidak ada satu variabel independen yang memiliki nilai VIF lebih dari 10. Jadi dapat disimpulkan bahwa tidak ada multikolinearitas antar variabel independen dalam model regresi ini.

\section{Pengujian Hipotesis}

Adapun interpretasi dari persamaan regrasi adalah sebagai berikut:

1. Koefisien regresi Koleksi Perpustakaan adalah 0,212. Ber positif koefisiennya, artinya ada hubungan antara Koleksi Perpustakaan terhadap Kemampuan Literasi Informasi memiliki hubungan yang searah. Dengan kata lain, jika koleksi perpustakaan mengalami peningkatan kualitas (jenis koleksi dan tahu terbit) dan kuantitas (eksemplar), maka kemampuan literasi informasi mahasiswa akan meningkat. Peningkatan kualitas dan kuantitas koleksi pada perpustakaan, merupakan upaya dalam mewujudkan salah satu tujuan dari Universitas Pamulang, yakni untuk menghasilkan ilmu-ilmu dasar dan terapan yang berdaya guna untuk meningkatkan kesejahteraan bagi seluruh lapisan masyarakat. Untuk menghasilkan ilmu-ilmu dasar dan terapan, dibutuhkan referensi dan literature yang berkualitas. Hal ini pula akan berdampak positif pada tingkat kemampuan literasi informasi mahasiswa Universitas Pamulang.

2. Koefisien regresi Layanan Perpustakaan adalah sebesar 0,240. Bernilai positif koefisiennya, artinya hubungan antara Layanan Perpustakaan 
terhadap Literasi Informasi memiliki hubungan yang searah. Adanya peningkatan layanan perpustakaan merupakan langkah konkrit yang sejalan dengan misi Universitas Pamulang yaitu "Menyelenggarakan pendidikan akademik, vokasi, dan profesi bagi kelompok masyarakat kurang mampu secara ekonomi dan sosial".

\section{KESIMPULAN DAN SARAN}

\section{A. Kesimpulan}

1. Koleksi, layanan dan tenaga perpustakaan merupakan variabel yang saling berkaitan satu sama lain dalam rangka meningkatkan kemampuan literasi informasi pemustaka (pengguna perpustakaan) karena, koleksi merupakan sumber informasi yang dikemas dalam sebuah layanan sirkulasi dan referensi oleh tenaga perpustakaan yang professional.

2. Koleksi Perpustakaan memiliki hubungan yang positif terhadap kemampuan literasi informasi atau $\mathrm{H}_{1}$ dapat diterima.

3. Layanan Perpustakaan memiliki pengaruh yang positif terhadap Tingkat Kemampuan Literasi Informasi atau $\mathrm{H}_{2}$ dapat diterima.

4. Responden berpotensi memiliki literasi informasi yang cukup baik.

\section{B. Saran}

Dalam usaha meningkatkan potensi literasi mahasiswa Prodi S1 Manajemen maka Universitas Pamulang hendaknya :

1. Memberikan perhatian penuh kepada sirkulasi buku - buku pustaka baik cetak maupun online.
2. Menyediakan fasilitas yang memadai untuk kegiatan belajar dan mengajar mahasiswa seperti akses jurnal-jurnal baik dari lingkup nasional maupun internasional.

3. Mengikut sertakan pelatihan dan penyuluhan bagi tenaga perpustakaan.

\section{DAFTAR PUSTAKA}

ALA (American Library Association), Literacy, Diunduh dari http://www.ala.org/aboutaᄀla/mis sionpriorities/keyactionareas, pada tanggal 07/10/2016.

Association of College and Reserach Libraries (ACRL), "Information Literacy Competency Standards for Higher Education", diunduh dari http://www.ala.org/acrl/ acrlstandards/informationliteracy \%20cometency.htm. Pada tanggal 22 Desember 2017.

Hartaji, D. A. " Motivasi Berprestasi Pada Mahasiswa yang Berkuliah Dengan Jurusan Pilihan Orangtua. Fakultas Psikologi Universitas Gunadarma. (tidak diterbitkan)", 2012.

Hasugian, “ Dasar-dasar Ilmu Perpustakaan dan Informasi", USU Press, Medan, 2009.

Iman H. P., "Studi Komparatif Pentingnya Literasi Informasi Bagi Mahasiswa. Visi Pustaka Vol.15 No.2, 80-88", 2013.

Kemendikbud, "Undang-Undang RI No 12 Tahun 2012 Tentang Pendidikan Tinggi.(Online), 
(http://sipuu.setkab.go.id/PUUdo c/17624/UU0122012_Full.pdf', diakses 13 Desember 2017.

Krisnaldy, K., Pasaribu, V. L. D., \& Senen, S. (2019). PENGARUH BUDAYA ORGANISASI, LINGKUNGAN KERJA DAN IKLIM ORGANISASI TERHADAP MOTIVASI PEGAWAI DAMPAKNYA TERHADAP KEPUASAN KERJA. Jurnal Semarak, 2(2).

Kohar, A. , "Teknik Kebijakan Pengembangan Koleksi", Perpustakaan Nasional RI, Jakarta, 2003.

Latuputty, Hanna, "Cerdas di Era Informasi: Penerapan Literasi Informasi di Sekolah untuk Menciptakan Pembelajar Seumur Hidup, (Online), http://halatu putty.blogspot.com/2013/12/cerd as-di-era-informasipenerapan.html", diakses 19 Desember 2017.

Nasution, "Metode Penelitian Kualitatif Naturalistik", Rajawali, Jakarta, 1996.

Nugroho, B. A., "Strategi Jitu Memilih Metode Statistik Penelitian dengan SPSS", Andi, Yogyakarta, 2005.

Pasaribu, V. L. D., \& Krisnaldy, K. (2018). ANALISIS KEPUASAN JAMA'AH PADA KINERJA DEWAN KEMAKMURAN MASJID AL-HIDAYAH PERIODE TAHUN 2017. KREATIF: Jurnal IImiah Prodi Manajemen Universitas Pamulang, 6(4), 41-51.
Pasaribu, V. L. D., Krisnaldy, K., \& Warasto, H. N. (2020). Pengaruh Gaya Kepemimpinan, Disiplin Kerja Dan Kompensasi Terhadap Kinerja Pegawai (Studi kasus kelurahan Pisangan Ciputat). Disrupsi Bisnis, 3(1).

Perpustakaan Nasional RI, "Peraturan Kepala Perpusnas RI No. 13 Tahun 2017 tentang Standar Nasional Perpustakaan Perguruan Tinggi”, Jakarta, 2007.

Perpustakaan Nasional RI, "UndangUndang Republik Indonesia Nomor 43 Tahun 2007 tentang Perpustakaan", Jakarta, 2007.

Rakhmat, J., "Metode Penelitian Komunikasi", PT. Remaja Rosadakarya, Bandung, 2008.

Siregar, R., "Perpustakaan: Energi Pembangunan Bangsa", USU Press, Medan, 2004.

Sudjana, "Metoda Statistika", Tarsito, Bandung, 2005.

Sugiyono, "Metode Penelitian Bisnis", Alfabeta, Bandung, 2005.

Sugiyono, "Metode Penelitian Kuantitatif, Kualitatif dan R\&D”, Alfabeta, Bandung, 2005.

Taslimah, $\quad \mathrm{Y}, \quad$ "Pembinaan Pengembangan Literatur Perpustakaan Pengelolaan Perpustakaan Sekolah Menengah Umum", Perpustakaan, Jakarta, 1998. 